\title{
BRUHN, Jørgen. The Intermediality of Narrative Literature: Medialities Matter. London: Palgrave Macmillan, 2016, 137 p.
}

Francisco Bruno Rodrigues Silveira ${ }^{1}$ 1Universidade Federal do Ceará, Fortaleza, Ceará, Brasil

Jørgen Bruhn, docente do Departamento de Literatura Comparada na Universidade Linnaeus, Suécia, atua na área de teoria e crítica literária, intermidialidade e estudos sobre mídias, com ênfase nos estudos sobre adaptação fílmica. Foi responsável pela edição, em 2003, juntamente com Anne Gjelsvik e Eirik Frisvold Hansen de Adaptation Studies: New Challenges, New Directions. The Intermediality of Narrative Literature: Medialities Matter, publicado pela editora Palgrave Macmillan, em 2016, é sua mais recente produção na área de estudos intermidiáticos. No livro, Bruhn define o termo midialidade, em inglês mediality, e suas implicações nos processos de tradução envolvendo diferentes mídias e artes. O autor considera sua abordagem nova e de grande ajuda para o desenvolvimento deste emergente campo de investigação dentro dos Estudos da Tradução.

No primeiro capítulo do livro, Jørgen Bruhn (C) faz uma exposição dos tipos de textos e mídias que foram considerados nas pesquisas e estudos que deram origem ao livro. Ele comenta que priorizou textos relativamente recentes, entre a primeira metade do século 20 e as duas primeiras décadas do século 21 . Neste capitulo, também há exposição da literatura relacionada ao tema, que pode conferir ao leitor maior profundidade na perspectiva de estudo apresentada na obra. 
Em relação ao segundo capitulo, o autor apresenta termos teóricos e uma serie de definições associadas aos estudos relacionados à mídia e à importância e relevância deste tipo de abordagem no contexto da tradução. A definição dos termos é elencada de forma a permitir que os leitores tenham os conhecimentos necessários para as análises que são descritas nas páginas seguintes do livro. Há também exposição do tipo de metodologia que deve ser usada dentro das pesquisas relacionadas à intermidialidade.

Já no terceiro capitulo da obra, Bruhn descreve estudos de caso dentro do contexto dos estudos de mídia. Aqui são elencadas problematizações no que diz respeito a transferência de textos entre mídias diferentes bem como aspectos extralinguísticas e que dizem respeito a noções culturais nos processos tradutórios. $\mathrm{O}$ autor enfatiza a relação entre palavra e imagem e relata a importância de considerar que a recepção das mais variadas formas de narrativas em diferentes mídias pelo público alvo acontece heterogeneamente. Neste capitulo, há varias referências a outra publicação do autor, Seeing without understanding: Mediality aspects of literature and memory in Nabokov's Spring in Fialta.

No quarto capitulo também há a exposição de outro estudo de caso considerando a narrativa de diferentes mídias; entretanto, neste capítulo, há maior enfoque nos recursos estilísticos dentro do contexto da tradução intermidiática. É interessante perceber o cuidado do autor em escrever suas considerações a respeito do tema de uma forma bem didática, que possibilita o entendimento fácil para leitores que possam não ter taento domínio do assunto abordado no livro.

Considerando o quinto capitulo da obra, pode-se perceber que Jørgen Bruhn passa a descrever elementos relacionados especificamente aos roteiros das diferentes narrativas midiáticas. Bruhn descreve como a estrutura e estratégias usadas nos roteiros podem interferir na recepção das adaptações fílmicas e apresenta ideias relacionadas ao senso de valor das traduções envolvendo intermidialidade. 
O sexto capitulo é dividido em duas partes. Enquanto a primeira parte do capitulo relata a importância da contextualização no processo da tradução intermidiática e como os tradutores devem considerar as implicações deste processo nas diferentes culturas onde estas traduções serão vinculadas, na segunda parte, encontra-se a descrição dos elementos pré-textuais e pós-textuais nas narrativas intermidiáticas.

Na conclusão da obra, sétimo capítulo, o autor retoma os estudos de caso apresentados nos capítulos anteriores e reforça o argumento de que há muitos elementos que antecedem a construção de narrativas que transcendem diferentes mídias. Ele também relata que a metodologia usada e explicada no livro pode contribuir para o desenvolvimento dos estudos relacionados à intermodalidade. Bruhn conclui reforçando as muitas possiblidades considerando as narrativas intermidiáticas e os processos de tradução envolvendo as diferentes mídias.

De modo geral, a obra apresenta definições de termos e de metodologia dentro deste novo campo de pesquisa, a intermidialidade. A maior contribuição feita neste livro é a exposição do panorama envolvendo a tradução em diferentes mídias e o como este processo deve ser considerado dentro dos Estudos da Tradução. O autor consegue tratar de um tema novo de forma clara, o que possibilita que novos estudos e análises sejam feitas utilizando seus conceitos e exposições. A obra pode servir como bibliografia inicial para estudos envolvendo os processos de narração nas adaptações fílmicas e muitas outras formas de inter-relação entre as mídias. Em The Intermediality of Narrative Literature: Medialities Matter, há algumas referências a Remediation: Understanding New Media, de Bolter, que permitem perceber certo dialogismo entre conceitos já estabelecidos sobre narrativas midiáticas que foram refletidos e muito bem abordados por Bruhn.

Entretanto, Bruhn detém-se apenas em exemplos de literatura de língua inglesa, desconsiderando que a atividade tradutória ocorre em todo o mundo. Faz-se necessário considerar diferentes povos e 
línguas e suas atividades tradutórias para que a pesquisa científica neste campo possa ser ais eficiente e coerente.

The Intermediality of Narrative Literature: Medialities Matter constitui uma grande contribuição para o campo de Estudos da Tradução e diferentes mídias e deve ser leitura de base para futuras pesquisas sobre o tema, já que traz definições de importantes conceitos dentro deste campo de pesquisa e situa o leitor no tipo de metodologia que pode ser utilizada, além de apresentar uma linguagem bem didática e de fácil entendimento, mesmo para aqueles que não têm tanto conhecimento sobre o tema.

\section{Referências}

Bolter, J.D. e R. Grusin. Remediation: Understanding new media. Cambridge: MIT Press, 1999.

Bruhn, J. (A). "Dialogizing adaptation studies: From one-way transport to a dialogic two-way process". In: Bruhn, J. e Hanssen, E. F. (eds.). Adaptation studies: New challenges, new directions. London: Bloomsbury, 2013.

Bruhn, J. (B). Seeing without understanding: Mediality aspects of literature and memory in Nabokov's Spring in Fialta. Orbis Literarum, 2015.

Bruhn, J. (C). The Intermediality of Narrative Literature: Medialities Matter. London: Palgrave Macmillan, 2016.

Recebido em: 08/12/2018

Aceito em: 15/03/2019

Publicado em maio de 2019

Francisco Bruno Rodrigues Silveira. E-mail: fbrunors@gmail.com. ORCID: https://orcid.org/0000-0001-9115-7772

Cad. Trad., Florianópolis, v. 39, nº 2, p. 248-251, mai-ago, 2019. 